\title{
ESTADO E POBREZA NO CAMPO: TROCAS SIMBÓLICAS ENTRE DIREITO, DÁDIVA E DIVIDA
}

\author{
Recebido em 30/01/2020, aprovado em 13/03/2020 \\ 10.30612/mvt.v6i11.10970 \\ Geórgia Vieira de Sousa ${ }^{22}$ \\ João Miguel Diógenes de Araújo Lima²3
}

\begin{abstract}
RESUMO: O artigo busca reconhecer os traços marcantes das noçóes de direito, dádiva e dívida entre beneficiárias do Programa de Assistência Técnica e Extensão Rural (ATER) e Fomento, no âmbito do Plano Brasil Sem Miséria (PBSM), do Governo Federal, na zona rural do município de Itapajé, Ceará. A pesquisa tece uma discussão em torno dos avanços e das críticas à Política Social no Brasil e às políticas públicas focalizadas que atuam no quadro da pobreza rural. Através de fontes bibliográficas e documentais e de pesquisa campo, realizada de 2013 a 2015 e novamente em 2018, encontramos uma população rural pobre, de baixa escolaridade, vivendo da agricultura familiar e com renda per capita de $\mathrm{R} \$ 85,00$, que reconhece a participação em políticas sociais ao mesmo tempo como direito e como dádiva - de Deus ou dos técnicos do programa. Ressaltam-se, assim, as relações de dependência e as trocas simbólicas que atravessam a garantia de direitos básicos.
\end{abstract}

Palavras-chave: Direito. Dádiva. Políticas sociais. Plano Brasil Sem Miséria.

\section{STATE AND POVERTY IN THE COUNTRYSIDE: SYMBOLIC EXCHANGES BETWEEN RIGHTS, GIFT AND DEBT}

ABSTRACT: The paper seeks to analyze the notions of rights, donation and debt that feature among beneficiaries of the Technical Assistance and Rural Outreach Program (ATER) and Fomentation, within the scope of the Federal Government's Brazil Without Misery Plan (Plano Brasil Sem

\footnotetext{
22 Possui graduação em Pedagogia pela Universidade Estadual Vale do Acaraú - UVA (2010) e especialização em Gestão Escolar e Coordenação Pedagógica pela Faculdade de Tecnologia do Nordeste - FATENE (2010). Graduada em Serviço Social pelo Instituto Superior de Teologia Aplicada - INTA (2015) e especialista em Legislação Social e Políticas Públicas pela Pótere Social/ Faculdade Ratio (2018). Atualmente cursando especialização em Enfrentamento à Violência Contra a Mulher pela Escola de Saúde Pública do Ceará (ESP-CE).

23 Bacharel em Ciências Sociais (2011) e mestre em Sociologia (2014) pela Universidade Federal do Ceará, em Fortaleza. Pesquisador associado ao Laboratório Artes e Micropolíticas Urbanas (LAMUR)-UFC. Foi orientador (2017) e tutor (2019) nos cursos de pós-graduação Educação, Pobreza e Desigualdade Social da UFC. Atualmente em curso de aperfeiçoamento Investigación, transferencia y desarrollo en la universidad pública pelo Conselho Latino-Americano de Ciências Sociais (CLACSO).
} 
Miséria), in the rural area of the Itapajé municipality, state of Ceará. The discussion is built on the advances and criticisms attributed to Social Policy in Brazil, and particularly to 'focused' public policies that are present in the context of rural poverty. Through bibliographic and documentary sources and field research, carried out from 2013 to 2015 and again in 2018, we found a poor rural population, with low education, living on family agriculture and with a per capita income of $\mathrm{R} \$$ 85.00 (US\$ 20), who recognize the participation in social policies both as a right and as a gift - be it by God or by the program's personnel. The analysis highlights the relations of dependence and symbolic exchanges that underlie the guarantee of basic rights in rural Brazil.

Keywords: Gift. Rights. Social Policy. Brazil Without Misery Plan.

\section{ESTADO Y POBREZA EN EL CAMPO: INTERCAMBIOS SIMBÓLICOS ENTRE DERECHO, DON Y DEUDA}

RESUMEN: El artículo busca reconocer las características notables de las nociones de derecho, don y deuda entre los beneficiarios del Programa de Asistencia Técnica y Extensión Rural (ATER) y Fomento, dentro del alcance del Plan Brasil Sin Miseria (PBSM) del Gobierno Federal, en la zona rural del municipio de Itapajé, Ceará. La investigación teje una discusión sobre los avances y las críticas de la Política Social en Brasil y las políticas públicas enfocadas que funcionan en el contexto de la pobreza rural. A través de fuentes bibliográficas y documentales e investigaciones de campo (llevadas a cabo de 2013 a 2015 y nuevamente en 2018), encontramos una población rural pobre, con baja educación, que vivía de agricultura familiar y con un ingreso per cápita de R\$ 85 (US\$ 20), que reconoce la participación en políticas sociales como un derecho y también como don (regalo) de Dios o de los técnicos del programa. Así, se enfatizan las relaciones de dependencia y los intercambios simbólicos que subyacen a la garantía de los derechos básicos.

Palabras Clave: Derecho. Don. Política Social. Plan Brasil Sin Miseria.

\section{INTRODUÇÃO}

Observar a presença e a atuação do Estado no campo, na garantia de direitos e na implementação de políticas públicas, abre um caminho fértil para análises sobre a pobreza na zona rural e a noção de direito.

Segundo o Censo do Instituto Brasileiro de Geografia e Estatística (IBGE), em 2010, 16 milhôes de brasileiros viviam com renda mensal inferior a $\mathrm{R} \$ 77,00$ (setenta e sete reais), caracterizando-se como situação de extrema pobreza. Esta pesquisa se dedica a esse tema, aproximando-se de um programa governamental, o Plano Brasil Sem Miséria (PBSM), lançado em 2011 com o objetivo de superar a extrema pobreza no país.

$\mathrm{O}$ artigo aborda particularmente as relaçóes simbólicas que emergem durante a implantação de um programa social com enfoque no combate à pobreza extrema na zona rural do município de 
Itapajé24, localizado no semiárido do Ceará, região Nordeste do Brasil. Desse modo, mergulhamos particularmente nas relaçôes entre os sujeitos que movimentam o Estado - servidores, técnicos - e a população que é público-alvo do programa - os usuários (ou beneficiários).

$\mathrm{O}$ interesse pela pesquisa emergiu durante uma experiência de trabalho de um dos autores 4 deste artigo no PBSM em Itapajé, que teve início em 2013, quando chamou sua atenção que as mulheres participantes do Plano viam como "favores" os serviços que são, constitucionalmente, reconhecidos como direitos. O que sustenta essa perspectiva? Quais desdobramentos traz para a execução de programas sociais e políticas públicas na zona rural? O que perpassa as noçóes de direito, dádiva, dívida e favor em contextos de pobreza extrema? Instigados por essas questóes, este artigo se apoia em pesquisa empírica conduzida junto à Assistência Técnica e Extensão Rural (ATER) e Fomento no âmbito do Plano Brasil Sem Miséria, no município de Itapajé, no período de 2013 a 2015, com um período adicional de entrevistas com beneficiárias, realizadas em 2018.

Com isso, busca-se reconhecer os traços marcantes que dizem respeito à dádiva e à dívida, imbricadas no processo de participação de beneficiárias do Programa de Assistência Técnica e Extensão Rural (ATER) e Fomento em Itapajé, um programa construído na noção de direito. O Brasil Sem Miséria envolveu cerca de cem açóes, distribuídas em três grandes eixos de atuação: garantia de renda, acesso a serviços e inclusão produtiva.

Em Itapajé, foram contempladas duzentas e oitenta e seis (286) famílias com o PBSM - ATER e Fomento, as quais de forma quantitativa fizeram parte da pesquisa descritiva. Desse universo, aproximamo-nos de forma qualitativa de oito (8) famílias.

A dialética nos deu aporte para o desdobramento dos demais métodos da pesquisa. Para tal entendimento, foi imprescindível uma leitura da conjuntura local, a qual perpassou métodos voltados para cada objetivo proposto, sendo a dialética o primeiro: "A dialética fornece as bases para uma interpretação dinâmica e totalizante da realidade, já que estabelece que os fatos sociais não podem ser entendidos quando considerados isoladamente, abstratos de suas influências políticas, econômicas, culturais, etc." (GIL, 2008, p. 13).

O trabalho de campo, por sua vez,

[...] permite a aproximação do pesquisador da realidade sobre a qual formulou uma pergunta, e também visa a estabelecer uma interação com os diferentes "atores" (pessoas com as quais vamos trabalhar) que fazem parte da realidade. Assim sua finalidade é construir um conhecimento empírico, considerado importantíssimo para quem faz pesquisa social. (MINAYO, 2016, p. 56).

Com um enfoque na dimensão simbólica de programas sociais e políticas públicas, buscamos analisar o que influencia na percepção das políticas públicas como direito e as relaçóes implícitas que se dão entre beneficiárias e operadores do PBSM a partir de pesquisa empírica. Recorremos a fontes documentais sobre Política Social no Brasil e o PBSM, assim como fontes bibliográficas das Ciências Sociais e do Serviço Social, a fim de se embasar a discussão sobre pobreza e dádiva, a partir de informaçóes obtidas em livros, artigos científicos e em sites da internet pertencentes aos

24 Localizado na mesorregião do Norte Cearense, Itapajé está a aproximadamente $125 \mathrm{~km}$ da capital do estado, Fortaleza, e tem uma populaçáo estimada em 50 mil habitantes, segundo o Censo IBGE de 2010 - ou 52 mil habitantes na estimativa divulgada pelo instituto em 2019. 
Governos Federal, Estadual, Municipal, assim como dados relacionados às temáticas abordadas no presente trabalho.

O embasamento teórico para a pesquisa foi construído com Behring e Boschetti (2011) e outros autores que discorrem sobre a história da Política Social e da Política Pública, trazendo-nos uma teoria acerca das definiçóes e configuraçóes em que essas políticas ocorrem, desde sua implantação até os dias atuais. Sobre transferência de renda, Cobo (2012), Yazbek (2015) e o boletim do Ministério do Desenvolvimento Social e Combate à Fome (MDS, 2018). Ambas as autoras trazem à tona a discussão sobre as políticas focalizadas de transferência de renda, fazendo-nos refletir sobre o público alvo do programa e as formas de atuação dessa política. Para tratarmos sobre dádiva e dívida, norteamos nossa pesquisa com Mauss (1925) e Lanna (1996), os quais abordam a dádiva e a obrigação/costume de retribuir os favores, para refletirmos sobre os contextos em que esses são direitos preconizados em leis. Para a abordagem do Plano Brasil Sem Miséria, buscamos dados junto a relatórios do Ministério do Desenvolvimento Social e Combate à Fome (MDS), responsável pela aplicação e fiscalização do PBSM na Assistência Social. Através de dados e pesquisas encontrados no site do ministério, tivemos um direcionamento acerca da situação em que se encontram os índices de Itapajé.

Destacamos a importância deste estudo para técnicos de políticas públicas e para pesquisadores das Ciências Sociais, em virtude das análises sobre pobreza, trocas simbólicas, poder e políticas públicas, e do Serviço Social ${ }^{25}$, tendo em vista que a garantia dos direitos sociais - no rompimento do clientelismo e da visão de direitos como benesse - é uma potente configuração para a atuação de assistentes sociais.

\section{ESTADO, POBREZA E POLITICA SOCIAL}

Partimos da questão social, ou seja, o "[...] conjunto das expressões das desigualdades da sociedade capitalista madura [...] enquanto a apropriação dos seus frutos se mantém privada, monopolizada por uma parte da sociedade" (IAMAMOTO, 1999, p. 27) para tecermos o debate desta seção. Há uma complexa conexão entre Estado, questão social, concepção de pobreza e Política Social, em que forças se sobrepóem, entram em atrito e produzem contradições.

A definição conceitual de Estado, por exemplo, atravessou diversos momentos históricos. Segundo Oliveira e Quintaneiro (2001), amparadas na visão de Marx, o Estado na sociedade capitalista é entendido como uma luta de interesses entre as classes, formando um campo fértil para o desenvolvimento de açóes que priorizam benefícios (para uma ou outra classe, nunca simultaneamente), baseando-se em uma relação antagônica de vantagens que privilegiam em um determinado momento a classe dominante e, em outro, a classe dominada.

Nesse sentido, Yazbek analisa o Estado como (2015, p. 4):

[...] uma relação de forças, como uma arena de conflitos. Relação assimétrica e desigual que interfere tanto na viabilização da acumulação, como na reprodução

\footnotetext{
25 Tomazini e Leite (2016) analisaram a ascensão e a crise do programa em meio às disputas políticas no primeiro governo Lula (2003-2006), entre as pautas da segurança alimentar, da educaçáo e da assistência social. Na proposta de unificaçáo dos programas sociais da época em torno do Programa Bolsa Família, baseado na transferência de renda para a população pobre, o Programa Fome Zero perdeu espaço.
} 
social das classes subalternas. Na sociedade capitalista o Estado é perpassado pelas contradiçōes do sistema e assim sendo, objetivado em instituiçóes, com suas políticas, programas e projetos, apoia e organiza a reprodução das relaçóes sociais, assumindo o papel de regulador e fiador dessas relaçōes. A forma de organização desse Estado e suas características terão pois, um papel determinante na emergência e expansão estatal face aos interesses dos membros de uma sociedade.

A Política Social do Estado brasileiro foi constituída por diferentes concepçóes de pobreza. O cenário político, nos últimos 30 anos, tem sido permeado por açóes e programas governamentais de combate à pobreza e à fome, como a Ação da Cidadania Contra a Fome, a Miséria e pela Vida, lançada em 1993; e o Programa Fome Zero, principal ação do governo federal em 2003 e 2004, abrindo espaço para o Programa Bolsa Família (PBF)6 6. A pobreza foi alçada, nos anos 1990, ao patamar de "[...] 'problema técnico', capaz de ser contornado com cálculos, focalizaçóes e redistribuiçôes orçamentárias” (SPRANDEL, 2004, p. 91), um fenômeno decorrente de desigualdade social e concentração de renda, que poderia ser mitigado por políticas públicas e intervençôes governamentais embasadas na própria Política de Assistência Social e no monitoramento de indicadores e estatísticas.

Anteriormente, contudo, outras análises sociais deram o tom ao debate sobre as causas da pobreza no País. A miscigenação étnica, por exemplo, foi apontada, do final do século XIX ao começo do século XX, como causa da pobreza e de mazelas sociais no Brasil, ancorando- se numa leitura evolucionista de superioridade racial. Na década de 1940, por sua vez, a fome e a pobreza do Nordeste do Brasil, particularmente no campo, foram atribuídas às condiçóes climáticas naturais da região, como parte de um determinismo geográfico, uma visão que Josué de Castro esforçou-se para desmistificar e rechaçar:

Nem todo o Nordeste é seco, nem a seca é tudo, mesmo nas áreas de sertão. Há tempos que nos batemos para demonstrar, para incutir na consciência nacional o fato de que a seca náo é o principal fator de pobreza ou da fome nordestinas. Que é apenas um fator de agravamento agudo desta situação cujas causas são outras. Sáo causas mais ligadas ao arcabouço social do que aos acidentes naturais, às condiçóes ou bases físicas da região. (CASTRO, 1992, p. 260).

O “arcabouço social" da pobreza e da fome no Brasil, argumentou Castro (1992), assentava-se na monocultura, no latifúndio e no subdesenvolvimento, os pilares da questão agrária nacional, atrelada à questáo social (IAMAMOTO, 1999), como afirmamos anteriormente. Complementa-se esse quadro com o coronelismo, um sistema em que os proprietários de terra - os "coronéis" controlam o sistema político e a vida social através de uma rede de relaçóes de poder, “[...] resultado da superposição de formas desenvolvidas do regime representativo a uma estrutura econômica e social inadequada”, como argumentou Victor Nunes Leal (1997, p. 40). Tratava-se de "[...] um compromisso, uma troca de proveitos entre o poder público, progressivamente fortalecido, e a decadente influência social dos chefes locais, notadamente dos senhores de terras" (LEAL, 1997, p. 40), sobretudo atrelado à estrutura agrária, envolvendo também os trabalhadores rurais mais pobres em relaçóes de troca e dependência.

E é esse mesmo Estado, carregado de contradições, que se torna responsável pela regulação de programas, projetos e açóes, além de ser o principal fiador deles. Nesse entendimento, a Política 
Social será tratada como intervenção do Estado, contemplando as necessidades sociais básicas dos cidadãos, como moradia, alimentação, lazer, educação, saúde etc., sendo o governo aquele que executa as ações do Estado.

A Política Social expressa justamente os conflitos e as contradiçóes inerentes ao modelo capitalista vigente, haja vista que discrepâncias se fazem presentes nas expressões da questão social. A Política Social está, portanto, intimamente ligada ao contexto histórico da sociedade.

As políticas sociais e a formataçấo de padrôes de proteção social são desdobramentos e até mesmo respostas e formas de enfrentamento - em geral setorializadas e fragmentadas - às expressôes multifacetadas da questão social no capitalismo, cujo fundamento se encontra nas relaçóes de exploração do capital sobre o trabalho. A questão social se expressa em suas refrações (Neto, 1992) e, por outro lado, os sujeitos históricos engendram formas de seu enfrentamento. Contudo, sua gênese está na maneira com que os homens se organizam para produzir num determinado momento histórico, como vimos, o de constituição das relaçôes sociais capitalistas - e que tem continuidade na esfera de reprodução social. (BENRING; BOSCHETTI, 2011, p. 51-52).

Dito isso, percebemos que as políticas sociais, a própria questáo social e, nela, a expressão da pobreza são reflexos profundos da produção e reprodução social, dadas em um momento histórico, que incluem condiçôes de vida, de cultura e de produção da riqueza.

Ademais, antes dos anos 1930, as políticas sociais no Brasil não apresentavam caráter universal, sendo a questáo social enfrentada como caso de polícia e de ação filantrópica. Com o advento da industrialização, a Política Social no pós-1930 deu-se através de mudanças no intervencionismo estatal e da criação dos direitos sociais, sendo um de seus principais a criação da Consolidaçáo das Leis Trabalhistas (CLT), em $1943^{26}$. Esse período ficou conhecido como "cidadania regulada" (TEIXEIRA, 1985), pois, com o advento da carteira de trabalho, a cidadania estava voltada a atender apenas aos inseridos no mercado formal de trabalho.

Durante a ditadura militar (1964-1985), a Política Social passou por um processo de expansão e modernização. Nesse período tivemos ainda um sistema dual de acesso às políticas: para quem podia pagar e para quem não podia. Denomina-se esse período de "modernizaçáo conservadora", tendo em vista as mudanças no que diz respeito à economia e às principais atividades no país, mas sem levar em consideração as melhorias necessárias à vida da população, havendo concentração de renda e crescimento do desemprego (NETTO, 1998).

No fim dos anos de 1980 e principalmente durante os anos de 1990, as políticas sociais passaram por profundas transformaçóes. A partir do intenso envolvimento de estudantes e dos movimentos sociais, chega ao fim a ditadura e há um processo de redemocratização do país. Através da promulgação da Constituiçáo Federal (1988), a democracia passou a se concretizar com a garantia de direitos que antes não existiam.

Juntamente com ela, inaugura-se a Seguridade Social (Título VIII, Art. 193 a 204), composta pela Previdência Social (em caráter contributivo e filiação compulsória), a Saúde Pública (direito de todos e dever do Estado, independente de contribuição) e a Assistência Social (para quem dela necessitar, independente de contribuição). Esse tripé busca garantir açóes capazes de assegurar os mínimos sociais àqueles em situaçáo de risco e/ou vulnerabilidade social.

26 Desde 1943, passou por diversas mudanças, sendo as mais recentes em 2017, pelo governo Temer, com uma reforma que incluiu desde a criação da lei de terceirização até a possibilidade de grávidas trabalharem nos ambientes considerados insalubres (vide lei no 13.467/2017), e em 2019, no governo Bolsonaro, com liberação do trabalho aos domingos e feriados e cobrança de ao menos $7,5 \%$ ao INSS para quem recebe seguro- desemprego. 
Para Yazbek (2015, p. 04):

[...] a Política Social será abordada como modalidade de intervenção do Estado no âmbito de atendimentos das necessidades sociais básicas dos cidadãos, respondendo a interesses diversos, ou seja, a Política Social expressa relaçóes, conflitos e contradiçóes que resultam da desigualdade estrutural do capitalismo. Interesses que não são neutros ou igualitários e que reproduzem desigual e contraditoriamente relaçóes sociais, na medida em que o Estado náo pode ser autonomizado em relação à sociedade e as políticas sociais são intervençóes condicionadas pelo contexto histórico em que emergem.

Agora, mais que regular a economia, o Estado precisa amparar aqueles que não conseguem ter uma qualidade mínima de subsistência. Dessa forma, a intervenção estatal está intimamente ligada às açóes que possam garantir o atendimento de demandas básicas que são efetivadas a partir da execução de políticas sociais.

Mesmo com o grande avanço na democracia, representado pela Constituição Federal de 1988, as crises econômicas e as transformaçóes capitalistas incidiram sobre o aprofundamento da questáo social.

Essa relação entre Estado e Sociedade está expressa diante de paradoxos que, de um lado, tentam garantir os direitos preconizados na Carta Magna para seus cidadáos, e, de outro, tentam satisfazer os interesses do Capital. Diante disso, as medidas adotadas pelo Estado tiveram papel fundamental na realização de políticas sociais que caracterizam a ação dele como forma de minimizar as expressôes da questão social.

Nos primeiros anos da década de 1990, houve a regulamentação da Lei Orgânica da Assistência Social (LOAS), lei n ${ }^{\circ} 8.742$, de dezembro de 1993, que trouxe avanços importantes para a proteçáo social, tornando a assistência social direito do cidadão e dever do Estado. Dessa forma, os mínimos sociais passam a ser providos através de iniciativas públicas e da sociedade, garantindo o atendimento às necessidades básicas.

A Constituição Federal, em seu artigo $6^{\circ}$, vem tratar dos Direitos Sociais que se referem à "educação, a saúde, a alimentação, o trabalho, a moradia, o transporte, o lazer, a segurança, a previdência social, a proteção à maternidade e à infância, a assistência aos desamparados [...]" Desde então, temos, em lei, tais direitos assegurados.

Vale ressaltar que esse artigo representa um avanço inexorável, mas que se tornou, com o passar do tempo, algo vago e distante da prática. Condicionados à política neoliberal, esses direitos foram colocados em xeque, prevalecendo a ordem dominante: o capital e a burguesia.

Para Draibe (1993 apud BEHRING; BOSCHETTI, 2011, p. 155): “[...] isso significou uma ausência de política social? Claro que não, mas as formulaçóes de política social foram capturadas por uma lógica de adaptaçáo ao novo contexto. Daí decorre o trinômio do neoliberalismo para as políticas sociais - privatização, focalização/seletividade e descentralização.”

Nesse sentido, apesar dos avanços, a consolidação da Política Social se deu em direção contrária, conforme explanam Behring e Boschetti (2011, p. 160-161):

[...] essa imbricação histórica entre elementos próprios à assistência e elementos próprios ao seguro social poderia ter provocado a instituição de uma ousada 
seguridade social, de caráter universal, redistributiva, pública, com direitos amplos fundados na cidadania. Não foi, entretanto, o que ocorreu, e a seguridade brasileira, ao incorporar uma tendência de separação entre a lógica do seguro (bismarckiana) e a lógica da assistência (beveridiana), e não de reforço à clássica justaposição existente, acabou materializando políticas com características próprias e específicas que mais se excluem do que se complementam, fazendo com que, na prática, o conceito de seguridade fique no meio do caminho, entre o seguro e a assistência.

Podemos perceber que o caminho percorrido até agora por essas políticas sociais, ao invés de servirem para inclusão e garantia de direitos, acabaram por excluir e "selecionar" a população cada vez mais carente e vulnerável.

O fortalecimento da concepção de pobreza como problema técnico pavimentou o caminho para uma intervenção focalizada na dimensão da "extrema pobreza"8 e localizada "[...] fundamentalmente e de maneira mais severa [n]a área rural da região Nordeste do Brasil” (SILVA JÚNIOR, 2006, p. 276), num quadro socioeconômico que se perpetuava na ausência de políticas. Sendo assim necessário, segundo Sposati, Carvalho e Fleury (2012, p. 160): “[...] apreender a extensão da pobreza e os modos possíveis de erradica-la, constituídos a partir da leitura do real brasileiro no contexto do capitalismo tardio. A pobreza brasileira está dispersa em todo o território, exigindo modos diversos de intervenção [...]”.

Entramos nos anos 2000 com um Estado Capitalista intransigente e com a Política Social refém desse sistema econômico. Agora ela atua no sistema de focalizaçáo e com condicionalidades, tornando os indivíduos estigmatizados e forçados a se enquadrarem em algum padrão vigente de pobreza e extrema pobreza. É nessa época que as políticas de transferência de renda com condicionalidades ganham força e começam a fazer parte - indispensável - do cenário de políticas sociais, tais como o PBF, ancorando-se na educação como forte fator de superação da pobreza e desigualdade social, especialmente na zona rural:

É sabido que há uma forte interação entre renda e nível de escolaridade. A educação é sem dúvida alguma o focus principal de políticas estruturais de combate à pobreza rural. A expansão do sistema educacional e, principalmente, a melhoria dele, torna- se um instrumento fundamental na superação do problema da pobreza rural. (SILVA JÚNIOR, 2006, p. 287).

Com o pressuposto de inclusão e igualdade de oportunidades, as políticas sociais passaram por um processo de ascensão, tornando-se pauta prioritária na agenda dos políticos.

A maior parte dos países em desenvolvimento, como o Brasil, não adota nenhum tipo de benefício universal, prevalecendo a focalização. As justificativas para tal, em geral, referem-se às questôes financeiro-fiscais do país (escassez de recursos) e ideológicas (maior eficiência da focalizaçâo no combate à pobreza). Entretanto, ressalta-se que a maioria dos países que adotam programas focalizados (e seus sistemas de acompanhamento de condicionalidades) desconhece o custo global de operacionalização dos mesmos e há uma grande carência de pesquisas de 
avaliaçấo de impacto e eficiência desses programas no combate a pobreza vis-à-vis os programas universais (COBO, 2012, p. 46).

Observamos que, ao incluírem, acabam excluindo, pois sempre haverá alguém apto a participar da política que, todavia, ficou de fora por causa de critérios, os quais náo são fidedignos ao retratarem a real situação das famílias. Trabalhar de forma que sejam atingidas as metas propostas, focadas nos impactos e transformaçôes das famílias utilizando-se de "eficácia” e "efetividade", é um dos desafios enfrentados. Como identificar essas famílias? Quais critérios para seleção? Como garantir a veracidade das informaçôes? Essas são algumas dúvidas que põem em xeque a qualidade e seriedade de tais programas. É certo que há um grande investimento em tal empreitada, mas fato é que tamanho empenho não cobre os impasses e entraves apresentados por um contingente tão seleto, mas que ao mesmo tempo é falho e abrangente. Houve avanços significativos na garantia de direitos e, consequentemente, na melhoria de vida dos brasileiros, mas como de fato está acontecendo a materialização dessas políticas?

Para Cobo (2012, p. 48):

[...] de uma forma geral, os problemas de focalização surgem justamente quando os monetariamente pobres não apresentam as características relevantes que entram na construção dos indicadores (ineficiência horizontal) ou ainda quando há pessoas não pobres com tais características que acabam se tornando elegíveis sem o serem (ineficiência vertical). São os "falsos ruivos" ilustrados por Barr (2004, p. 217): se somente os ruivos sáo pobres e todos os ruivos são pobres, a focalização sobre os ruivos pode ser perfeita, sem vazão. Todavia, deve-se também assumir, nesse caso, que não haja qualquer tecnologia que permita ao indivíduo pintar o cabelo de ruivo [...].

O Estado capitalista apresenta tangentes para a saída da miséria total: através das políticas sociais privatizadas, focalizadas/seletivas e descentralizadas temos demandas distintas de atendimento (negro, pobre, mulher), ou seja, não há o fortalecimento das ações integradas, mas, sim, a secção de programas e projetos que atuam separadamente e simultaneamente, sem uma relaçáo entre si na prática. E mais, impóem-se às famílias direitos universalmente garantidos (por exemplo: acesso universal à saúde e matrícula em escola pública), agora transformados em condicionalidades, que por falha do Estado não chegam a sua plenitude. Com isso, segundo Behring e Boschetti (2011, p. 187), “[...] as consequências da combinação perversa entre recrudescimento da pobreza, suposta falta de recursos do Estado [...] e impactos para a cobertura das políticas sociais no Brasil são, portanto, realmente dramáticas".

Para além de tratarmos as políticas sociais na tríade já acima citada, temos ainda uma forte marca trazida historicamente e incorporada ao nosso dia-a-dia como prática comum e, muitas vezes, vista como obrigatória, sendo o elemento de fundamental importância para a discussão de nossa pesquisa: a relação entre favor e dívida.

Nas antigas civilizaçóes, “[...] as trocas e os contratos fazem-se sob a forma de presentes, em teoria voluntários, na realidade obrigatoriamente dados e retribuídos" (MAUSS, 1925, p. 51) e, atualmente, fazem parte da vida em sociedade, visto "o modo como o direito real permanece ainda hoje ligado ao direito pessoal” (MAUSS, 1925, p. 52). 
No âmbito das políticas sociais na zona rural, objeto desta pesquisa, é notório como são atravessadas pelo favor e pela beneficência. Muito embora o caminho traçado pela Assistência Social até chegar a ser Política de fato tenha sido ocupado, até bem pouco tempo atrás, pelas damas de caridade, a igreja e a filantropia, dentre outros, vale salientar que a contribuiçâo da vida em sociedade, baseada nas trocas simbólicas, também deu aporte para a perpetuação dessa relação.

Dito isto, cabe a seguinte reflexão: ao colocarem-se em prática as políticas sociais, existe preocupação em saber se elas estão produzindo cidadãos "emancipados" (conforme, muitas vezes, está escrito nos objetivos dessas políticas) ou estão apenas reproduzindo dependência e assimetrias de poder por meio de relaçóes de troca? Desenvolveremos essa discussão a seguir.

\section{O PLANO BRASIL SEM MISÉRIA A CRIAÇÃO DO PLANO}

O Plano Brasil Sem Miséria tinha um grande objetivo: retirar da situação de extrema pobreza 16,2 milhóes de pessoas que viviam com renda per capita mensal de $\mathrm{R} \$ 77,00$.

Criado na gestão da presidenta Dilma Rousseff, as estratégias para se alcançar tal finalidade perpassam pontos relevantes para a construção do PBSM.

O primeiro passo foi buscar dados no Censo Demográfico de 2010, o que proporcionou um diagnóstico, norteando as açóes do Plano. Com isso, o Censo foi capaz de alertar para diversas necessidades, dentre elas, a de políticas diferenciadas da cidade e do campo.

Utilizou-se o Cadastro Único para Programas Sociais (CadÚnico ${ }^{27}$, peça fundamental para o planejamento das açôes, pois a partir dele tiveram como localizar a população pobre e extremamente pobre. Através de seu questionário socioeconômico, tornou-se possível a descrição de quem são, o que fazem, onde vivem e em que situação estão os brasileiros e brasileiras mais vulneráveis.

As açôes apresentadas pelo conjunto dos Ministérios finalizaram o planejamento e elaboração do Plano Brasil Sem Miséria - tendo como base os três eixos: garantia de renda, acesso a serviços e inclusão produtiva (sendo este subdividido em Urbana e Rural) - o ponto alfa para a criação do Decreto de $n^{\circ} 7.492$, de 02 de junho de 2011, que instituiu o Plano 1010.

De maneira geral, o Plano objetivava elevar a renda mensal per capita das famílias extremamente pobres, ampliar o acesso aos serviços públicos e açóes de cidadania e bem- estar social, e melhorar o acesso às oportunidades de ocupação e renda através de açôes de inclusão produtiva nos meios urbano e rural.

Para Castel (2005), o Estado intervém através das políticas sociais para minimizar as consequências do capitalismo. Ao mesmo tempo em que a burguesia é beneficiada com o consumismo e o lucro, a classe operária padece pela ausência de seguros sociais que possam lhe garantir o mínimo para a subsistência. Cobo (2012) dialoga com essa visão de Estado e complementa:

\footnotetext{
27 Instituído em julho de 2001 (Decreto n³.877), sendo atualmente regulamentado pelo decreto n.6.135 de 26 de junho de 2007. Neste, é definido como o instrumento de identificação e caracterização socioeconômica das famílias brasileiras de baixa renda, a ser obrigatoriamente utilizado para seleção de beneficiários e integração de programas sociais do governo federal voltados ao atendimento desse público-alvo. Tal obrigatoriedade, no entanto, não se estende aos programas administrados pelo Instituto Nacional do Seguro Social (INSS), sendo facultada a utilização do CadÚnico apenas na operacionalização do Benefício de Prestação Continuada (BPC) (COBO, 2012).
} 
[...] de acordo com Castel (2005), todo Estado moderno é mais ou menos obrigado a "fazer social" para mitigar algumas disfunçóes gritantes e assegurar um mínimo de coesão entre os grupos sociais, intervindo no mercado para que a provisão dos serviços de proteção social seja economicamente eficiente. E isso se dá não somente em relação aos seguros sociais, mas também nas políticas de alívio da pobreza, considerando que os custos da pobreza também geram ineficiências econômicas (como externalidades negativas), além, claro, dos argumentos de equidade e justiça social. (COBO, 2012, p. 33)

O Estado atua de maneira a dirimir essa desigualdade, na busca de garantir um bem-estar na sociedade e equilibrar a economia, pois, conforme visto, existe uma dualidade entre essas açóes. $\mathrm{O}$ Plano Brasil Sem Miséria não foge à regra e atuou na garantia de serviços sociais, individuais, comunitários e econômicos. Envolveu cerca de cem ações, distribuídas em três grandes eixos de atuação: garantia de renda, acesso a serviços e inclusão produtiva - todos acompanhados da estratégia de busca ativa por beneficiários.

O eixo de garantia de renda estava relacionado às transferências de dinheiro feitas para as famílias objetivando reduzir, em caráter imediato, a situação de extrema pobreza, tendo como destaque o PBF, o Benefício de Prestação Continuada (BPC) e Aposentadoria e a Ação Brasil Carinhoso.

O eixo seguinte, de acesso a serviços, tratava da qualificação, ampliação e provimento dos serviços e açóes de cidadania e de promoção de bem-estar, também voltados ao público em extrema pobreza, atuando em três grandes áreas da saúde, educação e assistência social.

O último eixo abordava a inclusão produtiva, atuando na oferta de oportunidades e renda. As atividades aconteciam na zona urbana e rural: Zona Urbana - com o Programa Nacional de Acesso ao Ensino Técnico e Emprego (PRONATEC Brasil Sem Miséria) e o Programa Nacional de Promoção do Acesso ao Mundo do Trabalho (Acessuas Trabalho); Zona Rural - serviços de Assistência Técnica e Extensão Rural (ATER), o Programa de Fomento a Atividades Rurais, entre outros.

\section{PLANO BRASIL SEM MISÉRIA NO MUNICÍPIO DE ITAPAJÉ}

O município onde a pesquisa foi realizada localiza-se na região Norte do Estado do Ceará, na regiáo serrana entre o Vale do Curu e a Serra de Uruburetama, a $125 \mathrm{~km}$ de Fortaleza, capital do Estado (FIGURA 1). É um município de Pequeno Porte II - de acordo com a Política Nacional de Assistência Social (PNAS), por ter menos de 50.000 habitantes. Segundo dados do IBGE de 2010 sua população é de 48.350 habitantes, com densidade demográfica de 110,01 hab./ $/ \mathrm{km}^{2}$; tem uma área geográfica de $430,565 \mathrm{~km}^{2}$ e faz limites com os municípios de Itapipoca e Uruburetama (norte); Tejuçuoca (sul); Uruburetama, Umirim e Pentecoste (leste); e Irauçuba (oeste). 
Figura 1 - Mapa populacional do estado do Ceará, com destaque para a localização do município de Itapajé. Fonte: IBGE11 (2020), com base no Censo de 2010.
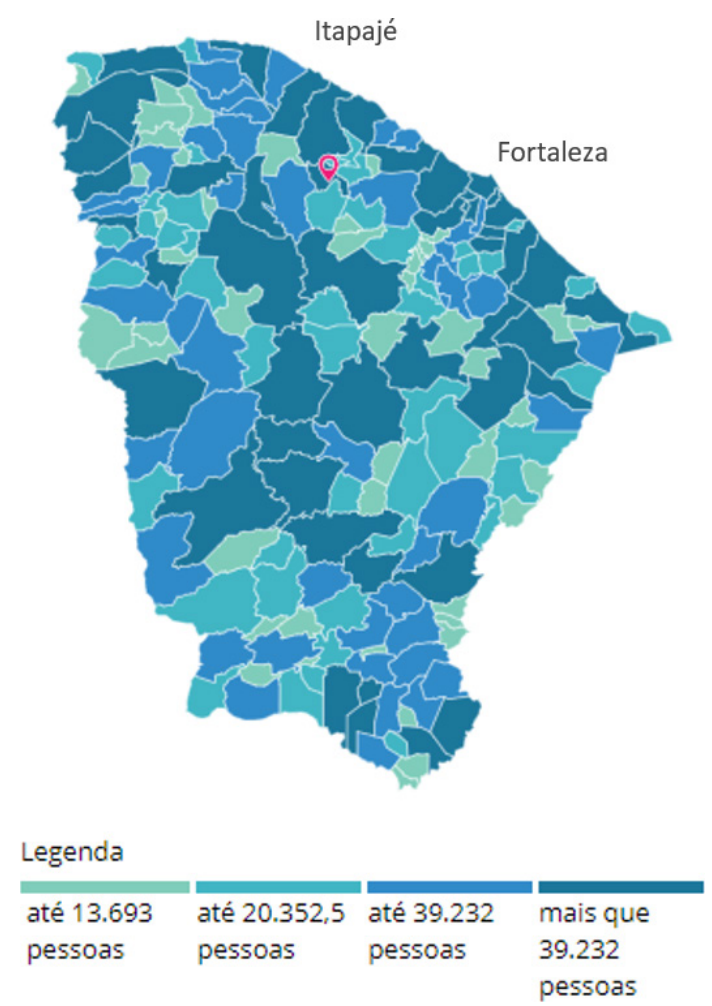

A economia da cidade sustenta-se na agricultura (banana, caju, mandioca, milho e feijão); pecuária (bovino, suíno e avícola) e artesanato (bordado). Conta, ainda, com uma grande fábrica de calçados, que é responsável pelo maior número de empregos com carteira assinada na cidade. $\mathrm{O}$ município subdivide-se em onze distritos, a saber: Itapajé (sede), Aguaí, Iratinga, Santa Cruz, Baixa Grande, Soledade, Pitombeira, Serrote do Meio, São Tomé, Armador e Mulungu.

O público beneficiado com o PBSM - ATER e Fomento no município, conforme já citado, foi de 286 famílias, sendo oito (8) as participantes da pesquisa qualitativa, no distrito de Soledade. Os dados abaixo tabulados dizem respeito às características domiciliares, da família e do acesso a políticas públicas do total de beneficiários cadastrados.

De acordo com a pesquisa feita, possuíam uma faixa de renda de até $\mathrm{R} \$ 170,00$ per capita, com domicílios na zona rural do município. As famílias eram nucleares ou extensas/ampliadas, sendo compostas principalmente por pai, mãe, filhos e netos. O grupo populacional tradicional ao qual pertenciam é denominado "agricultores familiares".

As tabelas a seguir reproduzidas foram extraídas do site do Ministério do Desenvolvimento Social e Agrário, através da plataforma TABCAD ${ }^{28}$, com dados sistematizados pela Secretaria de Avaliação e Gestão da Informação (SAGI). Os dados apresentados são de março de 2018 e trazem à pesquisa uma clarificação acerca das condiçóes que vivem as famílias pesquisadas nas variáveis escolaridade e principal ocupação.

28 Tabulador de Informaçóes do Cadastro Único (TABCAD). Disponível em: https://aplicacoes.mds.gov.br/sagi/cecad/tabulador_tabcad.php\#tabela_link 
Tabela 1: Função principal e Grau de instrução dos componentes da família

\begin{tabular}{|c|c|c|c|c|c|c|c|c|}
\hline \multirow[t]{2}{*}{ Função principal } & \multicolumn{7}{|c|}{ Grau de instrução } & \multirow[t]{2}{*}{ Total } \\
\hline & Sem instrução & $\begin{array}{l}\text { Fundamental } \\
\text { incompleto }\end{array}$ & $\begin{array}{l}\text { Fundamental } \\
\text { completo }\end{array}$ & $\begin{array}{c}\text { Médio } \\
\text { incompleto }\end{array}$ & $\begin{array}{l}\text { Médio } \\
\text { completo }\end{array}$ & $\begin{array}{c}\text { Superior } \\
\text { incompleto ou } \\
\text { mais }\end{array}$ & $\begin{array}{l}\text { Sem } \\
\text { resposta }\end{array}$ & \\
\hline $\begin{array}{l}\text { Trabalhador por } \\
\text { conta própria } \\
\text { (bico, autônomo) }\end{array}$ & $4,0 \%$ & $4,2 \%$ & $1,3 \%$ & $0,6 \%$ & $1,9 \%$ & $0,0 \%$ & $0,0 \%$ & $12,1 \%$ \\
\hline $\begin{array}{l}\text { Trabalhador } \\
\text { temporário em } \\
\text { área rural }\end{array}$ & $9,4 \%$ & $8,7 \%$ & $2,1 \%$ & $1,7 \%$ & $2,7 \%$ & $0,0 \%$ & $0,0 \%$ & $24,7 \%$ \\
\hline $\begin{array}{c}\text { Empregado } \\
\text { sem carteira de } \\
\text { trabalho } \\
\text { assinada }\end{array}$ & $0,0 \%$ & $0,0 \%$ & $0,2 \%$ & $0,0 \%$ & $0,0 \%$ & $0,0 \%$ & $0,0 \%$ & $0,2 \%$ \\
\hline $\begin{array}{l}\text { Empregado com } \\
\text { cart. de trabalho } \\
\text { assinada }\end{array}$ & $0,0 \%$ & $0,0 \%$ & $0,2 \%$ & $0,0 \%$ & $0,0 \%$ & $0,0 \%$ & $0,0 \%$ & $0,2 \%$ \\
\hline $\begin{array}{l}\text { Trabalhador } \\
\text { doméstico sem } \\
\text { cart. de trabalho } \\
\text { assinada }\end{array}$ & $0,0 \%$ & $0,0 \%$ & $0,0 \%$ & $0,0 \%$ & $0,0 \%$ & $0,0 \%$ & $0,0 \%$ & $0,0 \%$ \\
\hline $\begin{array}{l}\text { Trabalhador } \\
\text { doméstico com } \\
\text { cart. de trabalho } \\
\text { assinada }\end{array}$ & $0,0 \%$ & $0,0 \%$ & $0,0 \%$ & $0,0 \%$ & $0,0 \%$ & $0,0 \%$ & $0,0 \%$ & $0,0 \%$ \\
\hline $\begin{array}{l}\text { Trabalhador não- } \\
\text { remunerado }\end{array}$ & $1,3 \%$ & $1,5 \%$ & $0,2 \%$ & $0,0 \%$ & $0,8 \%$ & $0,0 \%$ & $0,0 \%$ & $3,8 \%$ \\
\hline $\begin{array}{c}\text { Militar ou servidor } \\
\text { público }\end{array}$ & $0,0 \%$ & $0,0 \%$ & $0,0 \%$ & $0,0 \%$ & $0,0 \%$ & $0,0 \%$ & $0,0 \%$ & $0,0 \%$ \\
\hline Empregador & $0,0 \%$ & $0,0 \%$ & $0,0 \%$ & $0,0 \%$ & $0,0 \%$ & $0,0 \%$ & $0,0 \%$ & $0,0 \%$ \\
\hline Estagiário & $0,0 \%$ & $0,0 \%$ & $0,0 \%$ & $0,0 \%$ & $0,2 \%$ & $0,0 \%$ & $0,0 \%$ & $0,0 \%$ \\
\hline Aprendiz & $0,0 \%$ & $0,0 \%$ & $0,0 \%$ & $0,0 \%$ & $0,0 \%$ & $0,0 \%$ & $0,0 \%$ & $0,0 \%$ \\
\hline $\begin{array}{c}\text { Sem } \\
\text { resposta }\end{array}$ & $13,9 \%$ & $19,5 \%$ & $7,3 \%$ & $6,2 \%$ & $6,7 \%$ & $0,0 \%$ & $5,2 \%$ & $58,8 \%$ \\
\hline Total & $28,7 \%$ & $33,9 \%$ & $11,3 \%$ & $8,5 \%$ & $12,3 \%$ & $0,0 \%$ & $5,2 \%$ & $100 \%$ \\
\hline
\end{tabular}

Fonte: Reproduzida a partir de dados gerados no TABCAD, plataforma do Ministério do Desenvolvimento Social e Agrário (BRASIL, 2018), gerada com dados de março de 2018.

Com a tabela 1, pode-se perceber que a principal função exercida é a de trabalhador temporário em área rural. Tendo em vista que a maioria das propriedades é cedida ou alugada, os agricultores trabalham por diárias ou empreitada. Em seguida, temos o trabalhador por conta própria - importante destacar que essa "autonomia" apenas caracteriza a agricultura de subsistência, ligada à produção para consumo próprio e não para comercialização. Grande parte da comunidade assistida pelo programa tem como grau de instrução o fundamental incompleto; apenas uma pequena parte terminou o ensino médio. 
Tabela 2: Faixa da renda familiar per capita e Função principal das famílias

\begin{tabular}{|c|c|c|c|c|c|c|c|c|c|c|c|c|c|}
\hline \multirow{2}{*}{$\begin{array}{l}\text { Faixa de renda familiar } \\
\text { per capita }\end{array}$} & \multicolumn{12}{|c|}{ Função principal } & \multirow[t]{2}{*}{ Total } \\
\hline & 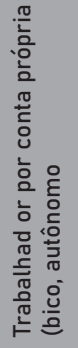 & 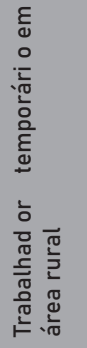 & 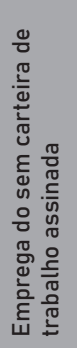 & 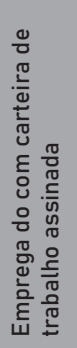 & 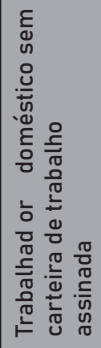 & 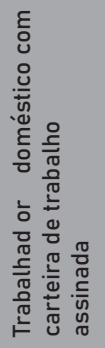 & 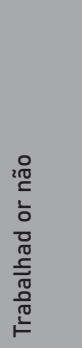 & 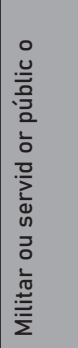 & 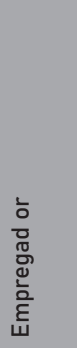 & 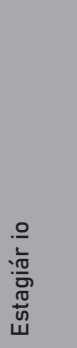 & 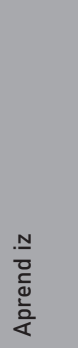 & 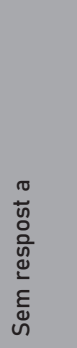 & \\
\hline $\begin{array}{l}\text { Até } \\
\text { R\$85,0 }\end{array}$ & $12,8 \%$ & $23,4 \%$ & $0,3 \%$ & $0,0 \%$ & $0,0 \%$ & $0,0 \%$ & $3,9 \%$ & $0,0 \%$ & $0,0 \%$ & $0,0 \%$ & $0,0 \%$ & $32,6 \%$ & $73,0 \%$ \\
\hline $\begin{array}{l}\text { Entre } \mathrm{R} \$ 85,01 \text { e } \mathrm{R} \$ 170 \text {, } \\
00\end{array}$ & $3,9 \%$ & $10,9 \%$ & $0,0 \%$ & $0,3 \%$ & $0,0 \%$ & $0,0 \%$ & $1,4 \%$ & $0,0 \%$ & $0,0 \%$ & $0,3 \%$ & $0,0 \%$ & $10,3 \%$ & $27,0 \%$ \\
\hline De R\$170, 01 e 1/2 S.M. & $00.0 \%$ & $00.0 \%$ & $00.0 \%$ & $00.0 \%$ & $00.0 \%$ & $00.0 \%$ & $00.0 \%$ & $00.0 \%$ & $00.0 \%$ & $00.0 \%$ & $00.0 \%$ & $00.0 \%$ & $00.0 \%$ \\
\hline Acima de $1 / 2$ S.M. & $0.0 \%$ & $0.0 \%$ & $0.0 \%$ & $0.0 \%$ & $0.0 \%$ & $0.0 \%$ & $0.0 \%$ & $0.0 \%$ & $0.0 \%$ & $0.0 \%$ & $0.0 \%$ & $0.0 \%$ & $0.0 \%$ \\
\hline Sem Resposta & $0,0 \%$ & $0.0 \%$ & $0.0 \%$ & $0.0 \%$ & $0.0 \%$ & $0.0 \%$ & $0.0 \%$ & $0.0 \%$ & $0.0 \%$ & $0.0 \%$ & $0.0 \%$ & $0.0 \%$ & $0.0 \%$ \\
\hline Total & $16,7 \%$ & $34.5 \%$ & $0.3 \%$ & $0.3 \%$ & $0.0 \%$ & $0.0 \%$ & $5.3 \%$ & $0.0 \%$ & $0.0 \%$ & $0.3 \%$ & $0.0 \%$ & $42.9 \%$ & $100.0 \%$ \\
\hline
\end{tabular}

Fonte: Reproduzida a partir de dados gerados no TABCAD, plataforma do Ministério do Desenvolvimento Social e Agrário (BRASIL, 2018), gerada com dados de março de 2018.

$\mathrm{Na}$ tabela 2, a faixa de renda familiar situa-se entre a extrema pobreza e a pobreza, sendo quantificada em $\mathrm{R} \$ 85,00$ por pessoa. Com relação ao acesso a políticas públicas, a comunidade conta com um posto de saúde e uma escola de ensino fundamental, e é assistida por um Centro de Referência da Assistência Social (CRAS) que não se localiza na comunidade, mas, sim, na sede do município.

Levando-se em consideração esses aspectos, temos uma população rural de baixa escolaridade, que vive da agricultura de subsistência, tem como moradia uma casa cedida ou alugada e uma renda per capita $\mathrm{R}$ \$ 10,00 acima da linha da extrema pobreza, o que nos faz refletir sobre as condiçôes de vida a que essas famílias estão submetidas e a dependência de políticas públicas para a garantia de direitos básicos para sua sobrevivência. Frente a isso, como essas políticas são vistas na comunidade e que relaçôes elas suscitam são as questóes que instigam o próximo tópico.

\section{TROCAS SIMBÓLICAS ENTRE DIREITO, DÁDIVA E DÍVIDA}

No período de 24 a 27 de abril de 2018, foram realizadas as entrevistas. Visitamos oito famílias beneficiadas pelo PBSM em suas casas, localizadas na zona rural do município de Itapajé. O PBSM, por adotar a intersetorialidade com o CadÚnico, operava também com a mãe (ou o responsável legal pela família) como titular do benefício, por diversos fatores: por ser a pessoa que estava em casa durante as visitas dos técnicos, ter (historicamente) mais responsabilidade para com sua prole e por ser a titular do cartáo do PBF, mesmo cartáo que recebia as parcelas referentes ao fomento do PBSM. Desse modo, foram entrevistadas oito mulheres, representantes de suas famílias ${ }^{29}$.

Nas entrevistas com as beneficiárias, nós nos deparamos com depoimentos carregados de significado para as questóes de nossa pesquisa. Algumas dessas falas serão apresentadas a seguir.

A pergunta inicial era sobre o acesso às políticas públicas. Houve unanimidade na resposta: todas têm ou tiveram acesso, principalmente, às políticas de educação e de saúde, tendo como 
principal forma de ingresso a escola e o posto de saúde, respectivamente. Ao indagarmos sobre a necessidade de ajuda para acessar tais políticas, a Beneficiária 1 ( 44 anos) nos disse: "Precisa de ajuda porque o negócio lá tá meio complicado. A gente chegar se tiver uma ajuda entra logo, se não tiver fica esperando horas e horas e vamos esperar! Eu tenho aquela ajuda, né? Mas e o pessoal? Tá complicado ali”30.

Já a Beneficiária 4 (48 anos) relatou: "Às vezes dá certo, às vezes não dá. Depende muito do caso."

$\mathrm{Na}$ conversa com as famílias, pudemos perceber que o atendimento às políticas públicas, em alguns casos, é resolvido pela própria pessoa que procura acessá-la, mas, em outros, faz-se necessária a troca de "favores". A Beneficiária 1 indicou acesso "facilitado" a uma política como favorecimento por conhecer alguém que trabalha num dado equipamento público, motivo pelo qual a troca simbólica perpetua-se na perspectiva do não acesso e do não reconhecimento das políticas públicas como direito. Sabemos que não é tarefa fácil modificar essa concepção enraizada em nossa sociedade, principalmente quando o direito individual se sobrepóe ao direito coletivo.

Quando indagadas sobre a relação que tinham com os técnicos do PBSM, afirmaram:

Graças a Deus era boa, entreguei tudo direitinho. Quando ele veio atrás dos recibos eu dei. Sempre tratava ele bem e dava almoço, dava arroz da serra, era tudo bom. (Beneficiária 1, 44 anos)

Acompanhava bem direitinho e dava as informaçóes. Eu gostava de sempre agradar porque eles eram legal comigo. Resolvia meus poblema e eu sempre tinha uma coisa guardada para eles. (Beneficiária 2, 52 anos)

Me deram uma orientação muito boa. De manhazinha, sempre converso com meu marido, e eu dizia a ele que esses menino me deram uma dica boa de comprar uma máquina nova e não uma usada. $\mathrm{O}$ que eu podia fazer por eles, eu fazia. Dava almoço, simples do nosso jeito. Eu gostava muito quando eles vinham. (Beneficiária 3, 47 anos)

Indagadas sobre essas trocas simbólicas, todas disseram que os técnicos não pediam algo em troca, mas que elas, as beneficiadas, sentiam-se na obrigação de retribuir, já que eles estavam acompanhando e orientando as famílias atendidas. Tratar bem, acolher, dar um almoço, repartir um pouco do que se ganhava: na visão das beneficiadas, não era nada mais que agradecer pela oportunidade de participar do programa.

Sobre entenderem o programa como um direito ou não, as entrevistadas responderam-nos:

Acho que era um direito e chegou na hora certa, porque eu merecia. Na hora que eu tava necessitando mesmo. (Beneficiária 1, 44 anos)

Eu acho que eles me ajudaram e eu era baixa renda e eu fui beneficiada. Ainda tenho a máquina que comprei, trabalho com ela. Foi bom demais! $\mathrm{Na}$ época

30 Priorizamos uma transcrição fidedigna às particularidades do discurso oral das entrevistadas 
não fui besta, tirei uma parte e fiz meu banheiro e o resto comprei as coisas do programa. (Beneficiária 2, 52 anos)

Pra mim foi uma bondade mandada por Deus! Encontrei na bíblia que tudo é na hora certa, vi minhas vizinhas recebendo e eu sabia que minha hora iria chegar. (Beneficiária 3, 47 anos)

Deus que me ajudou! (Beneficiária 5, 44 anos)

Seis beneficiárias atribuíram os atendimentos e os recursos recebidos a uma dádiva vinda de Deus, não reconhecendo, assim, que se configuravam como direito. Quatro, dentre as entrevistadas, reconhecem que estavam no perfil especificado e que atendiam aos critérios do programa, sendo que duas delas também atribuíram a uma "obra de Deus". Assim, pudemos perceber a influência da religião para essas famílias: mesmo reconhecendo a participação no PBSM como um direito, também agradeciam a Deus pela inserção no programa, transformando a ação em dádiva e, consequentemente, em dívida para com as pessoas que colaboraram para isso - a saber, os técnicos do programa.

$\mathrm{Na}$ época de vigência do PBSM, havia a equipe responsável pela assistência técnica voltada para o manejo, o cultivo e a aplicação do fomento (formada por veterinário, zootecnista e técnico em assistência técnica e extensão rural) e também a equipe responsável pela área social (composta por assistente social, pedagogo, cientista social, entre outras graduaçóes que faziam parte da área de humanas). As atividades deste setor consistiam em esclarecer às beneficiárias, através de palestras e visitas de orientação, acerca de outros programas que faziam parte do PBSM e que elas poderiam acessar por estarem naquele perfil. O objetivo maior da área social era mostrar que, além do programa ora contemplado, o acesso a remédios e a benefícios eventuais, por exemplo, estava preconizado em lei e que elas poderiam participar sem necessidade de terceiros para torná-las beneficiárias.

Esse é, particularmente, o papel primordial dos assistentes sociais, conforme orientação do código de ética da profissão, de 1993: fazer com que os usuários tenham acesso a políticas, a fim de efetivar seus direitos, não somente na perspectiva de ingresso, mas de permanência e atendimento até que uma demanda seja sanada, numa perspectiva de autonomia e emancipação dos indivíduos.

Por outro lado, o dar e o receber da dádiva implicam em sentimento de dívida e demandam uma retribuição: "[...] as trocas e os contratos fazem-se sob a forma de presentes, em teoria voluntários, na realidade obrigatoriamente dados e retribuídos”, como analisou Mauss (1925, p. 51) no estudo de práticas da civilização escandinava e de outras civilizações. A assimetria é "[...] o elo entre o conceito de troca de dádivas de Mauss e as infinitas elaboraçóes nativas” (LANNA, 1996, p. 131).

Teresa Sales (1994), retomando autores como Gilberto Freyre e Sergio Buarque de Holanda, discutiu a desigualdade social presente nas relaçôes de mando e subserviência, o que constituiria uma "cultura da dádiva”. Esta, por sua vez, numa perspectiva republicana, teria pavimentado uma "cidadania concedida" no Brasil.

Para Marcos Lanna (1996, p. 112), está implícito no "Ensaio sobre a dádiva", de Marcel Mauss, que reciprocidade e hierarquia "[...] devem ser entendidas como correlatas, faces de uma mesma moeda". Baseando-se em pesquisas prévias que realizou com patróes e trabalhadores no Nordeste brasileiro, analisando as relaçóes de patronagem e compadrio, e apoiando-se em pesquisadores que também se dedicaram ao estudo das trocas, como Claude Lévi-Strauss, Marshall Sahlins e Louis 
Dumont, Lanna (1996) propôs o conceito de "reciprocidade hierárquica" para analisar esses contextos de trocas. Por um lado, ressalta que "[...] a essência do sistema capitalista não é dada pela norma de reciprocidade, mas sim pela generalização da categoria 'mercadoria'" (LANNA, 1996, p. 118), como postulou Marx; por outro lado, o Estado do sistema capitalista coexiste com um regime de trocas e sua obrigação assimétrica de dar e retribuir.

Behring e Boschetti (2011, p. 190) salientam que:

É importante concluir esta discussão apontando que a política social, no contexto do capitalismo em sua fase madura, não é capaz de reverter esse quadro, nem é essa sua funçáo estrutural. Contudo, levar as políticas sociais ao limite de cobertura numa agenda de luta dos trabalhadores é tarefa de todos que têm compromissos com a emancipação política e a emancipação humana, tendo em vista elevar o padrão de vida das maiorias e suscitar necessidades mais profundas e radicais. Debater e lutar pela ampliação dos direitos e das políticas sociais é fundamental porque engendra a disputa pelo fundo público, envolve necessidades básicas de milhōes de pessoas com o impacto real nas suas condições de vida e trabalho e implica um processo de discussão coletiva, socialização da política e organização dos sujeitos políticos.

Desse modo, as relaçóes de troca que acontecem no contexto das políticas públicas, principalmente na zona rural dos municípios, convivem com a baixa escolaridade e o escasso acesso aos direitos sociais. O agradecimento a Deus e o presente dado aos técnicos do PBSM são elementos que reforçam uma relação pessoal com a Política, que se apoia na dimensão interpessoal, em detrimento da Política como direito social. Assim, fortalecem o favor, a dependência e o clientelismo, num momento histórico em que os direitos sociais sofrem cortes no Brasil.

\section{CONSIDERAÇÕES FINAIS}

Na pesquisa, pudemos perceber a força com que as relaçóes movidas pelas noções de dádiva e de dívida fazem-se presentes na sociedade contemporânea, em particular na zona rural do Brasil. Com o passar do tempo, ganharam uma nova roupagem, sem perder a dimensão simbólica.

Através das entrevistas na pesquisa de campo, vimos essa prática ainda presente, muito embora não mencionada diretamente. A busca por presentear aqueles que materializam o acesso ao PBSM implica em relação de troca inconsciente, de base assimétrica, muitas vezes não percebida pelos envolvidos e, consequentemente, enraizada nas relaçóes sociais.

Na perspectiva do Serviço Social, é importante desconstruir a visão do acesso às políticas sociais como "favores". Na consolidação do Estado democrático de direito, reconhecer o acesso ao programa estudado (e, de modo mais amplo, às políticas sociais) como um direito constitucional aos cidadãos é uma grande conquista.

Uma vez que a cultura política da dádiva está voltada para a perpetuação da dependência e do clientelismo, fortalecer a conscientização da população sobre seus direitos e acesso às políticas pode viabilizar uma mudança na cultura da troca simbólica.

Apesar da ascensão dessas políticas sociais, sabemos que existem desafios, assim como possibilidades de avanços: mesmo considerando a tendência de redução, essa situação de pobreza representa 
um percentual grande na cidade e maior ainda no campo, tornando necessária a ampliaçáo de métodos e técnicas voltados para a diminuição e erradicação dela. Mas não somente isso, a mudança efetiva esperada é constituída de oportunidades através de educação, fomentos e acesso a diversos serviços públicos, mas também no estímulo ao protagonismo, para que assim possam instruir cidadáos de direito, ampliando e consolidando a cidadania e rompendo com a dependência e a pobreza, que fortalecem assimetrias de poder imbricadas nas relaçôes sociais.

\section{REFERÊNCIAS}

BEHRING, Elaine; BOSCHETTI, Ivanete. Política Social: fundamentos e história. Biblioteca Básica do Serviço Social, v. 2. São Paulo: Cortez, 2011.

BRASIL. Decreto 6.135/07, de 26 de junho de 2007. Dispóe sobre o Cadastro Único para Programas Sociais do Governo Federal. Diário Oficial da União, 2007. Brasil, 2007.

. Instituto Brasileiro de Geografia e Estatísticas - IBGE. Brasília, 2010. Disponível em: https://www. ibge.gov.br/geociencias-novoportal/por-cidade-estado- geociencias.html?t=destaques\&c=2306306. Acesso em: 12/03/2018.

Lei 8.742/93, de 08 de dezembro de 1993. Dispóe sobre a Lei Orgânica da Assistência Social. Diário Oficial da Uniāo, 1993. Brasil, 1993.

. Ministério do Desenvolvimento Social e Agrário. Tabulador de Informações do Cadastro Único. Secretaria de Avaliaçáo e Gestão da Informação. Disponível em: https://aplicacoes.mds.gov.br/sagi/cecad/ tabulador_tabcad.php\#tabela_link. Acesso em: 10/04/2018.

. Constituição. Brasília: 1988.

. Ministério do Desenvolvimento Social e Combate à Fome. O Brasil sem miséria. Organizadores: Tereza Campello, TiagoFalcão, Patricia Vieira da Costa. - Brasília: MDS, 2014.

CASTEL, Robert. As metamorfoses da questão social: uma crônica do salário. 5. Ed. Trad. de Iraci Poleti. Petrópolis: Vozes, 2005.

CASTRO, Josué de. Geografia da fome - o dilema brasileiro: pão ou aço. 11 ed. Rio de Janeiro: Gryphus, 1992.

COBO, Barbara. Políticas focalizadas de transferência de renda: contextos e desafios. São Paulo: Cortez, 2012 .

DRAIBE, S. M. As políticas sociais brasileiras: diagnósticos e perspectivas para a década de 90. In: IPEA, Brasília: IPEA, 1990.

GIL, A. C. Métodos e técnicas de pesquisa social. 6 ed. São Paulo: Atlas, 2008.

IAMAMOTO, Marilda V. O Serviço Social na contemporaneidade; trabalho e formaçáo profissional. 2. ed. São Paulo: Cortez, 1999. 
LANNA, Marcos. Reciprocidade e hierarquia. Revista de Antropologia. Sáo Paulo: USP, v. 39, n. 1, p. 111-144, 1996. Disponível em: <http://www.revistas.usp.br/ra/article/view/111622/109660>. Acesso em 20 jan. 2020.

LEAL, Victor Nunes. Coronelismo, enxada e voto: o município e o regime representativo no Brasil. 3 ed. Rio de Janeiro: Editora Nova Fronteira, 1997.

MAUSS, Marcel. Ensaio sobre a dádiva. Forma e razão da troca nas sociedades arcaicas. Sociologia e Antropologia. V. II. São Paulo: Edusp, 1925.

MINAYO, Maria Cecília de Souza. Trabalho de campo: contexto de observação, interação e descoberta. In: (Org.). Pesquisa social: teoria, método e criatividade. Petrópolis, RJ: Vozes, 2016, p. 56-71.

NETTO, José Paulo. Ditadura e Serviço Social. São Paulo: Cortez, 1998.

QUINTANEIRO, Tania; BARBOSA, Maria Ligia de Oliveira; OLIVEIRA, Márcia Gardênia Monteiro. Um toque de clássicos: Marx, Durkheim e Weber. 2. ed. rev. amp. Belo Horizonte: Editora UFMG, 2002.

SALES, Teresa. Raízes da desigualdade social na cultura política brasileira. Revista brasileira de Ciências Sociais, n. 25, v. 9, São Paulo, jun. 1994.

SILVA JÚNIOR, Luiz Honorato da. Pobreza na população rural nordestina: uma análise de suas características durante os anos noventa. Revista do BNDES, Rio de Janeiro, v. 13, n. 26, p. 275-290, dez. 2006. Disponível em: Acesso em: 08 out. 2019.

SPOSATI, Aldaíza; CARVALHO, Maria do Carmo; FLEURY, Sônia. Os direitos (dos desassistidos) sociais. São Paulo: Cortez, 2012.

SPRANDEL, Marcia Anita. A pobreza no paraíso tropical: interpretaçóes e discursos sobre o Brasil. Rio de Janeiro: Relume-Dumará, 2004.

TEIXEIRA, Sonia Maria Fleury. Política Social e Democracia: reflexôes sobre o legado da seguridade social. Escola Brasileira de Administração Pública da Fundação Getúlio Vargas e escola Nacional de Saúde Pública Fio Cruz. Rio de Janeiro, 02/10/1985.

TOMAZINI, Carla Guerra; LEITE, Cristiane Kerches da Silva. Programa Fome Zero e o paradigma da segurança alimentar: ascensão e queda de uma coalizão?. Rev. Sociol. Polit., Curitiba, v. 24, n. 58, p. 13-30, jun. 2016. Disponível em: < http://dx.doi.org/10.1590/1678-987316245801>. Acesso em 8 Jan. 2020.

VIEIRA, Evaldo. Os direitos e a Política Social. São Paulo: Cortez, 2004. YAZBEK, Maria Carmelita. Estado e Políticas Sociais, 2015. Disponível em: https:/pt.slideshare.net/ThiagoPrisco/yazbek-maria-carmelita-estado-e-polticas-sociais-1. Acesso em: 12/03/2018. 